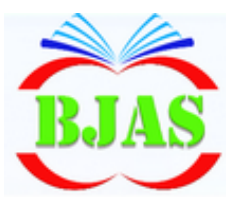

ISSN 1814-5868
Available online at http://www.bajas.edu.iq

https://doi.org/10.37077/25200860.2019.283

College of Agriculture, University of Basrah

DOi:10.21276/basjas
Basrah Journal

of Agricultural

Sciences

\title{
Effect of some Drip Irrigation System Design Parameters and some Soil Properties Relation to System Performance Evaluation, Growth and Productivity of Corn (Zea mays L.) Saturated Hydraulic Conductivity
}

\author{
Qasim B. I. Al-Yasiri" ${ }^{* 1}$ Dakhel R. Ndewi ${ }^{2}$ \& Ali H. Dheyab ${ }^{2}$ \\ ${ }^{1}$ Agriculture and Marshlands College, University of Dhi-Qar, Iraq. \\ ${ }^{2}$ Department of Soil Sciences, Agriculture College, University of Basrah, Iraq. \\ *Corresponding author e-mail: qassim@utq.edu.iq
}

Received 12 September 2019; Accepted 2 December 2019; Available online 26 December 2019

\begin{abstract}
A field experiment was conducted in Dhi-Qar Governorate, Al-Gharaf district, Al-Salem area adjacent to the Al-Gharaf river at longitude $31^{\circ} 17^{\prime} 55^{\prime \prime} \mathrm{N}$ and width $46^{\circ} 14^{\prime} 30 "$ E. This study was conducted in the autumn season of 2018 in claytexture soil, to evaluate some of the drip irrigation system design parameters in the hydraulic properties of system, soil characteristics, growth, and yield of corn (Zea mays L.), and the economic feasibility of each system, emitters discharge treatments $(2,4,6$ and $8 \mathrm{~L}_{\mathrm{hr}}{ }^{-1}$ ), the distance between the emitter treatments were 20,30 and $40 \mathrm{~cm}$, and the lengths of field pipes were 10,15 and $20 \mathrm{~m}$. The main results showed emitters discharge exceeded $8{\mathrm{~L} . h r^{-1}}^{\text {by }} 0.747 \mathrm{~m}^{- \text {day }^{-1}}$, whereas it was $0.612,0.512$ and 0.348 m.day ${ }^{-1}$ for the treatments 6,4 and $2 \mathrm{~L}^{-\mathrm{hr}^{-1}}$ respectively at the beginning of the growing season, while at the end of the season, the values were $0.907,0.701,0.589$ and 0.461

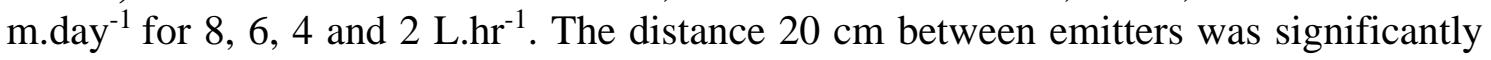
increasing in the hydraulic conductivity values by $11.92 \%, 32.98 \%$ compared with the 30 and $40 \mathrm{~cm}$ treatments, respectively, which amounted to $0.629 \mathrm{~m}^{-1 a y^{-1}}$. at the end of the season the values were $0.769,0.669$ and 0.539 m.day $^{-1}$ for 20,30 and $40 \mathrm{~cm}$ treatments respectively, while the treatment of field length of $10 \mathrm{~m}$ recorded the highest values at the beginning of the season by 0.661 the lowest values were 0.571 and 0.433 m.day $^{-1}$ respectively, with a decline of $13.61 \%, 34.49 \%$ compared to the treatment of 10 $\mathrm{m}$. At the end of the growing season, the values were $0.769,0.678$ and $0.547 \mathrm{~m}^{-d^{2}}{ }^{-1}$ for transactions 10,15 and $20 \mathrm{~m}$, respectively.
\end{abstract}

Keywords: emitters discharge, distance between emitters, pipe length, saturated hydraulic conductivity

\section{Introduction}

Drip irrigation system is a highly efficient process, depends on many factors, concerns the design standards of the system, plant type, soil, surrounding climatic and environmental conditions and availability of water sources, there were economic and human factors related to irrigation as the availability of labor, the price of cultivated product, the possibilities of marketing and the prices of fuel (Ghanimi \& Zuhairi, 2015). The most important hydraulic properties of the soil were saturated hydraulic conductivity, which is affected by some design standards of the drip irrigation system, which include emitters discharge, the distance between emitters, pipe length and soil properties. Ekhmaj \& 


\section{Al-Yasiri et al. / Basrah J. Agric. Sci., 32(Spec. Issue 2): 360-372, 2019}

Abdulaziz (2008) found increasing hydraulic conductivity with increasing of the discharge. Abdul Rahman \& Al-Sheikhli (2011) concluded that increasing in emitters discharge has a positive and significant effect on the values of saturated hydraulic conductivity, treatment of 3-day irrigation interval, $100 \%$ irrigation level and $5.35 \mathrm{~L} . \mathrm{hr}-1$ discharge in the highest saturated water conductivity rate of $3.07 \mathrm{~cm} \mathrm{~min}^{-1}$, while the treatment of 5-day irrigation interval, 50\% irrigation level and emitter discharge were recorded at 3.15 L.hr-1 lower for saturated hydraulic conductivity rate of $2.62 \mathrm{~cm} \mathrm{~min}^{-1}$. The main goal of this study is to investigate the effect of some design parameters of the drip irrigation system, emitters discharge, distance between emitters, and pipe length on the saturated hydraulic conductivity.

\section{Materials \& Methods}

A field experiment was conducted in Dhi-Qar Governorate, Al-Gharaf district, Al-Salem area, this investigation was conducted in the autumn season of 2018 in clay-texture soil. PVC main line $53.3 \mathrm{~mm}$ diameter, $50 \mathrm{~mm}$ sub main pipe and $16 \mathrm{~mm}$ field pipes (lateral), were used to ensure the required design discharge in the field. The network components were installed from the main conveyor pipe with a length of $100 \mathrm{~m}$, connected to three sub-tubes, $25 \mathrm{~m}$ for each tube.

Table (1): Main characteristics of soil and water irrigation.

\begin{tabular}{|c|c|c|c|c|}
\hline \multirow{2}{*}{\multicolumn{3}{|c|}{ Properties }} & \multicolumn{2}{|c|}{ Soil depth $(\mathrm{cm})$} \\
\hline & & & $0-20$ & $20-40$ \\
\hline \multicolumn{2}{|l|}{ Sand } & \multirow{4}{*}{$\mathrm{g} \mathrm{kg}^{-1}$} & 160.50 & 41.661 \\
\hline \multicolumn{2}{|l|}{ Silt } & & 333 & 343.13 \\
\hline \multicolumn{2}{|l|}{ Clay } & & 506.50 & 515.21 \\
\hline \multicolumn{2}{|l|}{ Texture } & & Clay & Clay \\
\hline \multicolumn{2}{|l|}{ Weighted diameter rate } & $\mathrm{mm}$ & 0.207 & 0.182 \\
\hline \multicolumn{2}{|l|}{ Particle density } & $\mathrm{mr}^{-3}$ & 1.391 & 1.415 \\
\hline \multicolumn{2}{|l|}{ Bulk density } & $\mathrm{mg} \mathrm{m}$ & 2.65 & 2.66 \\
\hline \multicolumn{2}{|l|}{ Total porosity } & $\%$ & 47.50 & 46.80 \\
\hline \multicolumn{2}{|c|}{ Soil resistance of penetration } & $\mathrm{KN} \mathrm{m}^{-2}$ & 972.84 & 1089.16 \\
\hline \multicolumn{2}{|c|}{ Total carbon } & $\mathrm{g} \mathrm{kg}^{-1}$ & 329.17 & 301.92 \\
\hline \multicolumn{2}{|l|}{ Organic mater } & $\mathrm{g} \mathrm{kg}^{-1}$ & 4.24 & 3.45 \\
\hline \multicolumn{2}{|c|}{ Humidity in Field capacity } & $\%$ & 32.13 & 30.55 \\
\hline \multicolumn{2}{|c|}{ saturated hydraulic conductivity } & m.day ${ }^{-1}$ & 0.426 & 0.308 \\
\hline \multicolumn{2}{|l|}{ ECe } & ds.m $m^{-1}$ & 5.30 & 5.87 \\
\hline \multicolumn{2}{|l|}{$\mathrm{pH}$} & & 7.76 & 7.81 \\
\hline \multirow{8}{*}{ dissolved ions } & $\mathrm{Ca}^{++}$ & \multirow{8}{*}{ mmole $\mathrm{L}^{-1}$} & 2.18 & 2.53 \\
\hline & $\mathrm{Mg}^{++}$ & & 8.12 & 8.87 \\
\hline & $\mathrm{Na}^{+}$ & & 30.85 & 37.87 \\
\hline & $\mathrm{K}^{+}$ & & 2.35 & 3.43 \\
\hline & $\mathrm{HCO}_{3}{ }^{-1}$ & & 3.21 & 4.18 \\
\hline & $\mathrm{SO}_{4}^{-2}$ & & 12.27 & 14.51 \\
\hline & $\mathrm{Cl}^{-}$ & & 28.02 & 34.01 \\
\hline & $\mathrm{CO}_{3}{ }^{-2}$ & & --- & ---- \\
\hline \multirow{2}{*}{\multicolumn{2}{|c|}{ Water irrigation }} & $\mathrm{EC} \mathrm{ds} \mathrm{m^{-1 }}$ & \multicolumn{2}{|c|}{1.87} \\
\hline & & $\mathrm{pH}$ & \multicolumn{2}{|c|}{7.60} \\
\hline
\end{tabular}




\section{Al-Yasiri et al. / Basrah J. Agric. Sci., 32(Spec. Issue 2): 360-372, 2019}

The end of each tube was placed by a piezometer, a transparent tube with a height of $1.50 \mathrm{~m}$, to regulating and standardizing operational pressure and discharge throughout the network, sub-tube was divided into 36 field tubes, (10, 15 and 20) $\mathrm{m}$ tube length according to treatment, $(2,4,6$ and 8$) \mathrm{L} \mathrm{hr}^{-1}$ emitter, interchangeably for each field pipe with a distance of $1.50 \mathrm{~m}$, three spaces between emitters $(20,30$ and 40$) \mathrm{cm}$ were used. The total experimental units in this study were 108. Factorial experiment designing with Randomized Complete Block Design (RCBD) were used to analysis the

$$
\mathrm{Ks}=\frac{\mathrm{V}}{\mathrm{At}} \times \frac{\mathrm{L}}{\mathrm{h}}
$$

Where:

$\mathrm{Ks}$, is a saturated hydraulic conductivity of soil $\left(\mathrm{cm} \mathrm{min}^{-1}\right)$;

$\mathrm{V}$, is the water volume of through the soil column $\left(\mathrm{cm}^{3}\right)$;

$\mathrm{L}$, is a length of soil column $(\mathrm{cm})$;

$\mathrm{A}$, is a surface area of the soil section $\left(\mathrm{cm}^{2}\right)$;

$\mathrm{t}$, is a time of measuring ( $\mathrm{min}$ );

$\mathrm{h}$, is a length of soil column + height of water column above the soil column $(\mathrm{cm})$.

\section{Results \& Discussion}

The results of the statistical analysis as shown in table (2) illustrated a highly significant effect of emitter discharge factor in the values of the saturated hydraulic conductivity at the beginning and end of the growing season. At the beginning of the season, the treatment of 8 L.hr-1 recorded the highest values by $0.747 \mathrm{~m}$ day $^{-1}$, while it was $0.612,0.512,0.348 \mathrm{~m}^{\text {day }}{ }^{-}$ 1 for transactions 6,4 and 2, L.hr ${ }^{-1}$, respectively, with a decrease of $18.07 \%$, $31.45 \%$ and $53.41 \%$ compared to the treatment $\left(8 \mathrm{~L}^{\mathrm{hr}} \mathrm{r}^{-1}\right)$. At the end of the season, the values were $0.907,0.701,0.589$ and 0.461 $\mathrm{m}$ day $^{-1}$ for $8,6,4$ and 2 L.hr-1. The relationship between saturated hydraulic conductivity has been expressed as a function of the drainage factor using straight line, equation 2 for the beginning of growing season with a coefficient of 0.992 and results statistically. Primary soil properties were measured as in table (1).

The saturated hydrological conductivity of soil was calculated with a cylindrical soil sample using the fixed water column method proposed by Klute described in Black et al. (1965), fixed a column of water above the unexcited soil column taken from the field by Core Sampler, amount of water passing through the column was then calculated for specific time periods until. The values of water were established with time. The values of soil water conductivity were calculated by the following equation:

(1) (Darcy law) equation 3 for the end of season with a coefficient of 0.980 , it was evident from them that the values of the saturated hydraulic conductivity increased by increasing the emitter discharge. Increasing of the saturated hydraulic conductivity is achieved by increasing the emitter discharge, due to the role of emitter discharge increasing in maintaining soil construction, by shifting and washing the salts horizontally towards the front of the moisturizing front, minimizing their negative impacts on the degradation and destruction of soil clusters, increase the size and area of moisture and porosity of the soil, thus increasing the values of saturated hydraulic conductivity (Abdul Rahman \& AlSheikhali, 2011). This is agreed with the assertion by Ekhmaj \& Abdulaziz (2008) that the increase in saturated hydraulic conductivity depends on soil properties and 


\section{Al-Yasiri et al. / Basrah J. Agric. Sci., 32(Spec. Issue 2): 360-372, 2019}

emitter discharge. In sandy soils it increased by increasing the emitter discharge to $6 \mathrm{~L}^{\mathrm{h}} \mathrm{hr}^{-1}$, while discharge decreased down to $2 \mathrm{~L}^{-\mathrm{hr}^{-1}}$ due to reduced volume and humidification space. Increase in saturated hydraulic conductivity values at the end of the growing season compared with the beginning of the increase of $32.47 \%, 15.03 \%, 14.54 \%$ and $21.14 \%$ for treatments $2,4,6$ and 8 L.hr' ${ }^{-1}$, respectively. This increasing in saturated hydraulic conductivity is due to the increase in the values of weighted diameter at the end

$$
\begin{gathered}
K s_{i}=0.231+0.065 Q \quad\left(R^{2}=0.992\right) \ldots \\
K s_{e}=0.302+0.073 Q \quad\left(R^{2}=0.980\right) \ldots
\end{gathered}
$$

Table (2): Statistical analysis of the $F$ test for saturated hydraulic conductivity at the beginning and end of the growing season.

\begin{tabular}{|c|c|c|c|}
\hline \multirow{2}{*}{ Source } & \multirow{2}{*}{ d.f } & \multicolumn{2}{|c|}{ saturated hydraulic conductivity (Ks) } \\
\cline { 3 - 4 } & & beginning of the season & end of the season \\
\hline Q & 3 & $798.56^{* *}$ & $964.76^{* *}$ \\
\hline S & 2 & $229.93^{* *}$ & $555.23^{* *}$ \\
\hline L & 2 & $493.85^{* *}$ & $451.74^{* *}$ \\
\hline D & 1 & $660.93^{* *}$ & $1123.05^{* *}$ \\
\hline Q.S & 6 & $7.34^{* *}$ & $10.07^{* *}$ \\
\hline Q.L & 6 & $4.90^{* *}$ & $4.20^{* *}$ \\
\hline S.L & 3 & $1.87^{\text {NS }}$ & $2.89^{*}$ \\
\hline Q.D & 4 & $24.09^{* *}$ & $1.92^{\text {NS }}$ \\
\hline S.D & 2 & $0.14^{\text {NS }}$ & $0.57^{\text {NS }}$ \\
\hline L.D & 2 & $1.00^{\text {NS }}$ & $1.85^{*}$ \\
\hline Q.S.L & 12 & $1.88^{*}$ & $0.81^{\mathrm{NS}}$ \\
\hline Q.S.D & 6 & $0.30^{\mathrm{NS}}$ & $0.90^{\mathrm{NS}}$ \\
\hline Q.L.D & 6 & $0.69^{\mathrm{NS}}$ & $0.46^{\mathrm{NS}}$ \\
\hline S.L.D & 4 & $0.11^{\mathrm{NS}}$ & $0.39^{\mathrm{NS}}$ \\
\hline Q.S.L.D & 12 & $0.28^{\mathrm{NS}}$ & \\
\hline Q: discharge of drippers (L.hr-1). S: distance between emitters (cm). L: field tube \\
length (m). D: depth of soil (cm).
\end{tabular}

There is a highly significant effect of the distance factor between the emitters on the values of saturated hydraulic conductivity at the beginning and end of growing season (results of statistical analysis of the F test of table 2). There was a significant difference between all transactions (tables $3 \& 4$ ), at the beginning of season, the treatment of $20 \mathrm{~cm}$ significantly increased the values of saturated hydraulic conductivity by $11.92 \%$ and $32.98 \%$ compared with the treatments $30 \mathrm{~cm}$ and $40 \mathrm{~cm}$ respectively, which amounted to $0.629 \mathrm{~m}^{- \text {day }^{-1}}$. At the end of season the values were $0.769,0.669$ and $0.539 \mathrm{~m}^{-d_{a y}}{ }^{-1}$ for 20 , 30 and $40 \mathrm{~cm}$ transactions respectively. The relationship between saturated hydraulic 


\section{Al-Yasiri et al. / Basrah J. Agric. Sci., 32(Spec. Issue 2): 360-372, 2019}

conductivity has been expressed as a function of the distance factor between emitters using season and a correlation coefficient of 0.993 and formula 5 for the end of the growing season with a treatment of 0.989 , shows that the values of the saturated hydraulic conductivity are reduced by increasing the distance between the emitters. The decreasing in the saturated hydraulic conductivity values due to the increase in the distance between the emitters, due to the low moisture content of the soil, the increase of soil salinity, the low weighted diameter rate, the increase of soil bulk density and the low porosity, reflected in the volumetric distribution of soil pores and consequently lower values of saturated hydraulic conductivity compared to converging distances, increase of the total root of the plant and the activity and effectiveness of microorganisms, degrade organic matter and bind soil clusters,

$$
\begin{aligned}
& K s_{i}=0.789-0.008 S \quad\left(R^{2}=0.993\right) \ldots(4) \\
& K s_{e}=1.035-0.012 S \quad\left(R^{2}=0.989\right) \ldots(5)
\end{aligned}
$$

The results of the statistical analysis of the $F$ test in Table 2 showed that the effect of the field tube length factor on the values of saturated aqueous conductivity was highly significant at the beginning and end of the growing season. There were significant differences between all the treatments (Tables 3 and 4), at the beginning of the season, the treatment of $10 \mathrm{~m}$ recorded the highest values by 0.661 m.day $^{-1}$ while the transactions of 15 and $20 \mathrm{~m}$ gave the lowest values by 0.571 and 0.433 m.day $^{-1}$ respectively, with a decrease of $13.61 \%$ and $34.49 \%$ compared to the treatment $10 \mathrm{~m}$. At the end of the growing season, the values were $0.769,0.678$ and $0.547 \mathrm{~m}^{\text {day }}{ }^{-1}$ for transactions 10,15 and 20 $\mathrm{m}$, respectively. The relationship between negative straight line formula 4 for the beginning of the growing increases the pores occupied by the roots, increase the movement of water, consequently, saturated aquatic conductivity increased (Schwartzman \& Zur 1986; Sarhan, 2009).

The results also showed an increase in saturated hydraulic conductivity at the end of the growing season compared to the beginning of the growing season; the increase was $24.96 \%, 19.03 \%$ and $13.95 \%$ for the 20 , 30 and $40 \mathrm{~cm}$ transactions respectively. This is due to the decrease in bulk density, electrical conductivity and the increase in the weighted end of the season, which was reflected in the increase in the saturated hydraulic conductivity at the end of the growing season compared to the beginning of the growing season.

saturated hydraulic conductivity was expressed as a function of the field length factor using straight line rates 6 and 7 with a coefficient of 0.985 and 0.989 for the beginning and end of the growing season, respectively. The increase in hydraulic conductivity values saturated by the low length of the field pipe is due to differences in soil moisture content and the weighted diameter rate of the field pipe length $10 \mathrm{~m}$ compared to 15 and $20 \mathrm{~m}$, thus improving soil properties was reflected in increasing the values of saturated hydraulic conductivity. This is agreeing with Al-Abdali (2019) who observed a decrease in saturated hydraulic conductivity when the field tube length increased from 30 to $60 \mathrm{~m}$.

$$
\begin{aligned}
& K s_{i}=0.897-0.023 L\left(R^{2}=0.985\right) \ldots(6) \\
& K s_{e}=0.998-0.022 L\left(R^{2}=0.989\right) \ldots(7)
\end{aligned}
$$




\section{Al-Yasiri et al. / Basrah J. Agric. Sci., 32(Spec. Issue 2): 360-372, 2019}

Increase in saturated hydraulic conductivity at the end of growing season compared to the beginning of the growth by $16.33 \%, 18.73 \%$ and $26.32 \%$ for treatments 10,15 and $20 \mathrm{~m}$, respectively. This is due to the low soil bulk density and increased porosity due to improved soil structure at the end of the growing season, as well as increased root growth and spread as plant growth advances and the formation of new pores that contribute to increased saturated hydraulic conductivity values (Evenylo \& Meguinn, 2000; Camillia et al., 2006). The results in tables (2-4) showed the variability of the values of saturated hydraulic conductivity with the depth of the soil, the higher clay and silt content in subsurface depths (Table 1). These results were in agreement with Hassan (2018), who superiority of depth $0-20 \mathrm{~cm}$ significantly with higher values of $0.631 \mathrm{~m}$.day ${ }^{-1}$ compared to the depth of $20-40 \mathrm{~cm}$ recorded 0.478 m.day ${ }^{-1}$ at The beginning of growing season. Whereas at the end of the growing season, the increase was $36.05 \%$ for treatment of $0-20 \mathrm{~cm}$ compared to treatment of $20-40 \mathrm{~cm}$. The relationship between saturated hydraulic conductivity was expressed as a function of soil depth factor using straight line equations 8 and 9 with a coefficient of 0.999 and 0.999 for the beginning and end of the growing season, respectively. The decreasing in the saturated hydraulic conductivity values at increased depth is due to high bulk density, reduced total porosity of the soil, as well as concluded that the values of saturated hydraulic conductivity increased by increasing in soil depth.

$$
\begin{gathered}
K s_{i}=0.631-0.008 D\left(R^{2}=0.999\right) \\
K s_{e}=0.766-0.010 D \quad\left(R^{2}=0.999\right)
\end{gathered}
$$

The results also showed an increase in saturated hydraulic conductivity at the end of growing season compared to the beginning of season with an increase of $21.39 \%$ and $17.78 \%$ for the treatments $0-20$ and $20-40$ respectively. The increase in the saturated hydraulic conductivity values at the end of the growing season is due to the growth of the total root plant and its divergence in the soil body, which helps the movement and penetration of the water through the soil (Atee, 2009). The results of the statistical analysis of the $\mathrm{F}$ test are show in the Table 2. There is a high significant effect of the interaction between the emitter discharge factor with different distances treatment in the values of saturated hydraulic conductivity at the beginning and end of growing season. As shown in tables 3 and 4 . There was a significant difference in the saturated hydraulic conductivity for the treatment of drip discharges 8 L.hr- ${ }^{-1}$ compared with treatments 6, 4 and 2 L.hr $^{-1}$, which varies according to the variability of distances between the emitters. The most significant differences were observing when the distance between the emitters was $20 \mathrm{~cm}$ compared to the 30 and $40 \mathrm{~cm}$. The highest values were when the drainage treatment was $8{\mathrm{~L} . h r^{-1}}^{-1}$ and the distance treatment was $20 \mathrm{~cm}$ at 0.804 and $1.009 \mathrm{~m}^{-d_{a y}}{ }^{-1}$ at the beginning and end of season respectively. The lowest values were 0.284 and 0.362 m.day ${ }^{-1}$ when the drainage

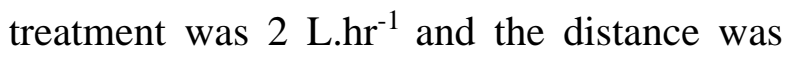
$40 \mathrm{~cm}$ at the beginning and end of the growing season, respectively. The increase in the saturated hydraulic conductivity was due to increased emitter discharge and close distances, moisture interaction, resulting in increased soil moisture retention between 


\section{Al-Yasiri et al. / Basrah J. Agric. Sci., 32(Spec. Issue 2): 360-372, 2019}

successive irrigation, reduced the impact of humidification and drying processes and their role in the degradation of soil construction due to the destruction of soil clusters, as a result of the humidification and drying processes during irrigation, physical soil properties such as increased aggregate stability, reduced soil bulk density, reduced soil salinity, increased emitters discharge and reduced spacing, the resulting saturated hydraulic conductivity increases (Al-Sadoun, 2006; Sarhan, 2009).
Polynomial formulas 10 and 11 with a coefficient of determination of 0.977 and 0.971 were used at the beginning and end of the growing season, respectively, to predict the values of saturated hydraulic conductivity as a function of the emitters discharge factors and the distance between the emitters, increased saturated hydraulic conductivity values were observed by increasing the emitters discharge and the small distance between emitters.

$$
\begin{aligned}
\mathrm{Ks}_{i} & =0.464+0.065 Q-0.008 S\left(R^{2}=0.977\right) \ldots \\
\mathrm{Ks}_{\mathrm{e}} & =0.673+0.073 \mathrm{Q}-0.012 \mathrm{~S}\left(\mathrm{R}^{2}=0.971\right) \ldots \ldots \ldots
\end{aligned}
$$

The results of the statistical analysis of the F test of Table 2 showed that there is a highly significant effect of the interaction between the emitter discharge treatments of field divergence by the field tube length in the saturated hydraulic conductivity values at the beginning and end of the growing season.

The variance in the values of saturated hydraulic conductivity according to the variations of the drips varies according to the length of the field pipe (Tables 3 and 4). The highest differences were found between the emitter discharge at the field length of $10 \mathrm{~m}$ compared to the lengths 15 and $20 \mathrm{~m}$. The values were increasing when the emitter discharge treatment was 8 L.hr $^{-1}$ for all pipe lengths compared with the corresponding pipe lengths for the remaining 6, 4 and 2 L.hr ${ }^{-1}$. The highest values were recorded when the emitter discharge treatment was $8{\mathrm{~L} . h r^{-1}}^{-1}$ and the $10 \mathrm{~m}$ field length was 0.876 and 1.035 m.day ${ }^{-1}$ at the beginning and end of growing season. While the lowest values when treated

$$
\begin{gathered}
K s_{i}=0.572+0.065 Q-0.023 L\left(R^{2}=0.981\right) \ldots \\
K s_{e}=0.673+0.073 Q-0.022 L\left(R^{2}=0.976\right) \ldots
\end{gathered}
$$

The results of the statistical analysis of the $\mathrm{F}$ test are showing in table (2). Increase in saturated hydraulic conductivity values decreases with increasing distance between 


\section{Al-Yasiri et al. / Basrah J. Agric. Sci., 32(Spec. Issue 2): 360-372, 2019}

emitters, the significant variance between the coefficients varies according to the length of the field pipe from 10 to 15 and then $20 \mathrm{~m}$ (Tables 3 and 4). The highest variations in saturated hydraulic conductivity values were found in the spacing between emitter's treatments when the length of the field pipe was $10 \mathrm{~m}$ while the lowest was $20 \mathrm{~m}$. The values were increasing when treating the field length of $10 \mathrm{~m}$ for all distances between emitters 20,30 and $40 \mathrm{~cm}$ compared with the corresponding distances at treatments 15, 20 $\mathrm{m}$. The highest values of saturated hydraulic conductivity were recorded when treating the distance of $20 \mathrm{~cm}$ and the length of the pipe $10 \mathrm{~m}$ by $0.895 \mathrm{~m}^{-d a y}{ }^{-1}$, the minimum value is $40 \mathrm{~cm}$ and the length of the pipe is $20 \mathrm{~m}$ by 0.436 m.day $^{-1}$. This is due to the balance of moisture speed resulting from the overlap of

$$
K s_{e}=1.368-0.012 S-0.022 L\left(R^{2}=0.988\right) \ldots(14)
$$

The results of the statistical analysis of the $F$ test are showing in Table 2. There was a high significant effect of the interaction between the emitter discharge treatments according to the depth of the soil in the values of saturated hydraulic conductivity at the beginning and end of the growing season. As shown in tables 3 and 4 , the significant differences in the values of saturated hydraulic conductivity between the emitter discharge treatments varies according to the depth of the soil. The highest variation was observing between emitter discharges treatments when treating soil depth $0-20 \mathrm{~cm}$ while the lowest variation was $20-40 \mathrm{~cm}$. The values were increased when treating the soil depth 0-20 cm for all the emitter discharges 2, 4, 6 \& 8 L.hr ${ }^{-1}$ compared with the corresponding expenses when treating soil depth 20-40 cm, the highest values were recorded at $0-20 \mathrm{~cm}$ depth by $0.852 \& 1.049$ $\mathrm{m} \mathrm{day}^{-1}$ when the emitter discharge treatment was 8 L.hr-1, the lowest values at depth were convergent distances and short pipes that did not lead to the deterioration of soil construction relatively, the result of rapid hydration while keeping the soil moist and maintaining a suitable moisture content between irrigation, preserve soil clusters, reflected positively in the high values of saturated water conductivity (Sarhan, 2009; Al-Abdali, 2019).

A polynomial formula 14 with a coefficient of 0.988 was used at the end of growing season, to predict the values of saturated hydraulic conductivity as a function of the distance factors between the emitters and the length of the field pipe, increased saturated hydraulic conductivity values are observed to be low both in the distance between the drippers and the length of the field pipe.

$20-40 \mathrm{~cm}$ by 0.292 and $0.391 \mathrm{~m}^{-d_{a y}{ }^{-1} \text { when }}$ treatment of emitter discharges was $2{\mathrm{~L} . h r^{-1}}^{-1}$ start and end of growing season, respectively. The increase in saturated hydraulic conductivity is due to the increased emitter discharge at the surface depth, role of increased discharge at this depth by increasing the spread of roots, the formation of new pores, contributes to increased effective channels of water conduction (Camillia et. al., 2006). As well as the change in total porosity and volumetric distribution of pores to subsurface depths, because of the weight of the upper layer and increased levels of cohesion and compression, because of high clay content, the bulk density increased and the values of saturated hydraulic conductivity decreased (Young et al., 1994). 
Al-Yasiri et al. / Basrah J. Agric. Sci., 32(Spec. Issue 2): 360-372, 2019

Table (3): Effect of treatments on saturated hydraulic conductivity $\left(\mathrm{m} . d a y^{-1}\right)$ before subsequent irrigation start of growth season.

\begin{tabular}{|c|c|c|c|c|c|c|c|c|c|c|c|c|c|c|c|c|c|}
\hline \multirow{2}{*}{\multicolumn{3}{|c|}{$\mathrm{Q}^{*} \mathrm{~L} * \mathrm{D}$}} & \multirow{2}{*}{\multicolumn{3}{|c|}{$\mathrm{Q} * \mathrm{~S} * \mathrm{D}$}} & \multirow{3}{*}{$\mathrm{Q} * \mathrm{D}$} & \multicolumn{3}{|c|}{20} & \multicolumn{3}{|c|}{15} & \multicolumn{3}{|c|}{10} & \multirow{2}{*}{\multicolumn{2}{|c|}{$\frac{\mathrm{L}}{\mathrm{S}}$}} \\
\hline & & & & & & & \multirow[t]{2}{*}{40} & \multirow[t]{2}{*}{30} & \multirow[t]{2}{*}{20} & \multirow[t]{2}{*}{40} & \multirow[t]{2}{*}{30} & \multirow[t]{2}{*}{20} & \multirow[t]{2}{*}{40} & \multirow[t]{2}{*}{30} & \multirow[t]{2}{*}{20} & & \\
\hline 20 & 15 & 10 & 40 & 30 & 20 & & & & & & & & & & & $\mathrm{D}$ & Q \\
\hline 0.273 & 0.421 & 0.518 & 0.334 & 0.421 & 0.457 & 0.404 & 0.242 & 0.263 & 0.313 & 0.319 & 0.441 & 0.502 & 0.441 & 0.537 & 0.556 & $20-0$ & 0 \\
\hline 0.173 & 0.306 & 0.369 & 0.234 & 0.298 & 0.342 & 0.292 & 0.142 & 0.163 & 0.213 & 0.219 & 0.308 & 0.392 & 0.341 & 0.404 & 0.422 & $40-20$ & 2 \\
\hline 0.472 & 0.576 & 0.630 & 0.490 & 0.553 & 0.633 & 0.559 & 0.416 & 0.474 & 0.525 & 0.507 & 0.553 & 0.666 & 0.548 & 0.633 & 0.708 & $20-0$ & 1 \\
\hline 0.372 & 0.482 & 0.541 & 0.401 & 0.453 & 0.540 & 0.465 & 0.316 & 0.374 & 0.425 & 0.407 & 0.453 & 0.586 & 0.481 & 0.533 & 0.608 & $40-20$ & 4 \\
\hline 0.585 & 0.738 & 0.808 & 0.598 & 0.702 & 0.831 & 0.711 & 0.481 & 0.593 & 0.682 & 0.620 & 0.733 & 0.862 & 0.695 & 0.779 & 0.950 & $20-0$ & 6 \\
\hline 0.374 & 0.527 & 0.641 & 0.398 & 0.524 & 0.620 & 0.514 & 0.291 & 0.393 & 0.448 & 0.410 & 0.533 & 0.629 & 0.494 & 0.646 & 0.784 & $40-20$ & 0 \\
\hline 0.725 & 0.862 & 0.970 & 0.768 & 0.879 & 0.909 & 0.852 & 0.612 & 0.774 & 0.788 & 0.786 & 0.886 & 0.913 & 0.907 & 0.978 & 1.0276 & $20-0$ & 8 \\
\hline 0.492 & 0.652 & 0.782 & 0.558 & 0.669 & 0.699 & 0.642 & 0.402 & 0.531 & 0.544 & 0.576 & 0.676 & 0.703 & 0.697 & 0.801 & 0.849 & $40-20$ & 8 \\
\hline \multicolumn{3}{|c|}{ NS } & \multicolumn{3}{|c|}{ NS } & 0.0236 & \multicolumn{9}{|c|}{ NS } & \multicolumn{2}{|c|}{ RLSD } \\
\hline \multicolumn{3}{|c|}{$\mathrm{L}$} & \multicolumn{4}{|c|}{$S$} & \multicolumn{3}{|c|}{20} & \multicolumn{3}{|c|}{15} & \multicolumn{3}{|c|}{10} & \multicolumn{2}{|l|}{$\mathrm{L}$} \\
\hline 20 & 15 & 10 & 40 & 30 & & & 40 & 30 & 20 & 40 & 30 & 20 & 40 & 30 & 20 & & \\
\hline 0.223 & 0.364 & 0.457 & 0.284 & 0.359 & & & 0.192 & 0.213 & 0.263 & 0.269 & 0.375 & 0.447 & 0.391 & 0.430 & 0.489 & 2 & \\
\hline 0.422 & 0.529 & 0.585 & 0.446 & 0.503 & & & 0.366 & 0.424 & 0.475 & 0.457 & 0.503 & 0.626 & 0.515 & 0.583 & 0.658 & 4 & \\
\hline 0.479 & 0.633 & 0.725 & 0.498 & 0.613 & & & 0.381 & 0.493 & 0.565 & 0.520 & 0.633 & 0.746 & 0.595 & 0.712 & 0.867 & 6 & \\
\hline 0.609 & 0.757 & 0.876 & 0.663 & 0.774 & & & 0.507 & 0.653 & 0.666 & 0.681 & 0.781 & 0.808 & 0.802 & 0.889 & 0.937 & 8 & \\
\hline & 0288 & & & 0.0 & & & & & & & 0.0500 & & & & & RLS & \\
\hline RLSD & 8 & 6 & 4 & 2 & (mean) & & $\mathrm{L}$ & & & & & & & $\mathrm{S}$ & & & \\
\hline 0.0167 & 0.747 & 0.612 & 0.512 & 0.348 & Q & 20 & 15 & 10 & $40-20$ & $20-0$ & S & L*D & 40 & 30 & 20 & D & $\mathrm{L}$ \\
\hline 00144 & & & 30 & 20 & (mean) & 0.492 & 0.657 & 0.738 & 0.550 & 0.708 & 20 & 0.731 & 0.648 & 0.737 & 0.810 & $20-0$ & 1 \\
\hline 0.0144 & & & 0.562 & 0.629 & $\mathrm{~S}$ & 0.446 & 0.573 & 0.669 & 0.486 & 0.639 & 30 & 0.590 & 0.504 & 0.601 & 0.666 & $40-20$ & 0 \\
\hline 00144 & & & 15 & 10 & (mean) & 0.361 & 0.482 & 0.576 & 0.398 & 0.548 & 40 & 0.649 & 0.558 & 0.653 & 0.736 & $20-0$ & 1 \\
\hline 0.0144 & & & 0.571 & 0.661 & $\mathrm{~L}$ & & NS & & & & RLSD & 0.492 & 0.406 & 0.493 & 0.578 & $40-20$ & 5 \\
\hline Q: Emitt & Disch & gge (L.h & 1), & S: Dista & e amon & emitters & m), & & & 5 (mean & & 0.51 & 0.438 & 0.526 & 0.577 & $20-0$ & 2 \\
\hline$L \cdot$ field $r$ & elenotl & $(\mathrm{m})$ & & D. & il deen & $\mathrm{m})$ & & & & & $20-0$ & 0.353 & 0.285 & 0.365 & 0.408 & $40-20$ & 0 \\
\hline & & & & & & & & & & & 0.631 & NS & & NS & & & \\
\hline & & & & & & & & & & 0.0118 & & & & IV & & & \\
\hline
\end{tabular}


Al-Yasiri et al. / Basrah J. Agric. Sci., 32(Spec. Issue 2): 360-372, 2019

Table (4) Effect of treatments on saturated hydraulic conductivity $\left(\mathrm{m} . d a y^{-1}\right)$ before subsequent irrigation end of growth season.

\begin{tabular}{|c|c|c|c|c|c|c|c|c|c|c|c|c|c|c|c|c|c|}
\hline \multirow{2}{*}{\multicolumn{3}{|c|}{$\mathrm{Q}^{*} \mathrm{~L}^{*} \mathrm{D}$}} & \multirow{2}{*}{\multicolumn{3}{|c|}{$\mathrm{Q} * \mathrm{~S} * \mathrm{D}$}} & \multirow{3}{*}{$Q^{*} \mathrm{D}$} & \multicolumn{3}{|c|}{20} & \multicolumn{3}{|c|}{15} & \multicolumn{3}{|c|}{10} & \multirow{2}{*}{\multicolumn{2}{|c|}{$\frac{\mathrm{L}}{\mathrm{S}}$}} \\
\hline & & & & & & & \multirow[b]{2}{*}{40} & \multirow[b]{2}{*}{30} & \multirow[b]{2}{*}{20} & \multirow[b]{2}{*}{40} & \multirow[b]{2}{*}{30} & \multirow[b]{2}{*}{20} & \multirow[b]{2}{*}{40} & \multirow[b]{2}{*}{30} & \multirow[b]{2}{*}{20} & & \\
\hline 20 & 15 & 10 & 40 & 30 & 20 & & & & & & & & & & & $\mathrm{D}$ & Q \\
\hline 0.399 & 0.548 & 0.645 & 0.414 & 0.551 & 0.627 & 0.531 & 0.322 & 0.393 & 0.483 & 0.399 & 0.571 & 0.672 & 0.521 & 0.687 & 0.726 & $20-0$ & \multirow{2}{*}{2} \\
\hline 0.287 & 0.398 & 0.487 & 0.310 & 0.389 & 0.472 & 0.391 & 0.242 & 0.277 & 0.343 & 0.282 & 0.388 & 0.522 & 0.405 & 0.504 & 0.552 & $40-20$ & \\
\hline 0.574 & 0.678 & 0.732 & 0.549 & 0.642 & 0.792 & 0.661 & 0.475 & 0.563 & 0.684 & 0.566 & 0.642 & 0.825 & 0.607 & 0.722 & 0.867 & $20-0$ & \multirow{2}{*}{4} \\
\hline 0.424 & 0.535 & 0.593 & 0.400 & 0.502 & 0.649 & 0.517 & 0.315 & 0.423 & 0.534 & 0.406 & 0.502 & 0.695 & 0.480 & 0.582 & 0.717 & $40-20$ & \\
\hline 0.698 & 0.852 & 0.921 & 0.658 & 0.812 & 1.001 & 0.824 & 0.5412 & 0.703 & 0.852 & 0.680 & 0.834 & 1.032 & 0.755 & 0.889 & 1.120 & $20-0$ & 6 \\
\hline 0.445 & 0.587 & 0.701 & 0.420 & 0.584 & 0.730 & 0.578 & 0.324 & 0.453 & 0.558 & 0.430 & 0.593 & 0.739 & 0.505 & 0.706 & 0.894 & $40-20$ & 0 \\
\hline 0.921 & 1.058 & 1.167 & 0.908 & 1.079 & 1.159 & 1.049 & 0.752 & 0.974 & 1.038 & 0.926 & 1.086 & 1.163 & 1.047 & 1.178 & 1.276 & $20-0$ & 8 \\
\hline 0.624 & 0.772 & 0.902 & 0.650 & 0.789 & 0.859 & \begin{tabular}{|l|}
0.766 \\
\end{tabular} & 0.515 & 0.651 & 0.704 & 0.656 & 0.796 & 0.863 & 0.777 & 0.921 & 1.009 & $40-20$ & 8 \\
\hline \multicolumn{3}{|c|}{ NS } & \multirow{2}{*}{\multicolumn{4}{|c|}{\begin{tabular}{c|c}
$\mathrm{NS}$ & 0.0240 \\
$\mathrm{~S}$ & \\
\end{tabular}}} & \multicolumn{9}{|c|}{ NS } & \multicolumn{2}{|c|}{ RLSD } \\
\hline \multicolumn{3}{|c|}{$\mathrm{L}$} & & & & & & 20 & & \multicolumn{3}{|c|}{15} & \multicolumn{3}{|c|}{10} & $\mathrm{~L}$ & \\
\hline 20 & 15 & 10 & 40 & 30 & \multicolumn{2}{|c|}{20} & 40 & 30 & 20 & 40 & 30 & 20 & 40 & 30 & 20 & & Q \\
\hline 0.343 & 0.473 & 0.566 & 0.362 & 0.470 & 0.55 & & 0.282 & 0.335 & 0.413 & 0.341 & 0.480 & 0.597 & 0.463 & 0.595 & 0.639 & 2 & \\
\hline 0.499 & 0.606 & 0.662 & 0.475 & 0.572 & 0.72 & & 0.395 & 0.493 & 0.609 & 0.486 & 0.572 & 0.760 & 0.544 & 0.652 & 0.792 & 4 & \\
\hline 0.572 & 0.720 & 0.811 & 0.539 & 0.698 & 0.86 & & 0.432 & 0.578 & 0.705 & 0.555 & 0.718 & 0.886 & 0.630 & 0.797 & 1.007 & 6 & \\
\hline 0.772 & 0.915 & 1.035 & 0.779 & 0.934 & 1.00 & & 0.634 & 0.813 & 0.871 & 0.791 & 0.941 & 1.013 & 0.912 & 1.049 & 1.142 & 8 & \\
\hline & 0.0294 & & & 0.0 & 94 & & & & & & 0.0509 & & & & & RLS & \\
\hline RLSD & 8 & 6 & 4 & 2 & $\mathrm{O}$ (mean) & & $\mathrm{L}$ & & & & & & & $\mathrm{S}$ & & & \\
\hline 0.0170 & 0.907 & 0.701 & 0.589 & 0.461 & & 20 & 15 & 10 & $40-20$ & $20-0$ & S & L*D & 40 & 30 & 20 & D & $\mathrm{L}$ \\
\hline 00147 & & & 30 & 20 & $\mathrm{~S}$ (mean) & 0.649 & 0.814 & 0.895 & 0.678 & 0.895 & 20 & 0.866 & 0.733 & 0.869 & 0.997 & $20-0$ & 10 \\
\hline $0.014 /$ & & & 0.669 & 0.786 & & 0.555 & 0.678 & 0.773 & 0.566 & 0.771 & 30 & 0.671 & 0.542 & 0.678 & 0.793 & $40-20$ & 10 \\
\hline & & & 15 & 10 & $\mathrm{~L}$ (mean) & 0.436 & 0.543 & 0.637 & 0.445 & 0.633 & 40 & 0.784 & 0.643 & 0.786 & 0.923 & $20-0$ & \\
\hline 0.0147 & & & 0.678 & 0.769 & & & 0.0254 & & & & RLSD & 0.573 & 0.444 & 0.570 & 0.705 & $40-20$ & 15 \\
\hline & & & & & & & & & & (mean & & 0.64 & 0.522 & 0.658 & 0.764 & $20-0$ & 20 \\
\hline O: Emitte & rs Disch & $\operatorname{rrge}(\mathrm{L}$. & & & & nitt & ) & & & & 20-0 & 0.445 & 0.349 & 0.451 & 0.535 & $40-20$ & 20 \\
\hline L: field $p$ & ipe leng & (m) & & स. DIS & Soil deep & $(\mathrm{cm})$ & (III), & & & & 0.766 & & & & & & \\
\hline & & & & & & & & & & 0.0120 & & NS & & NS & & & \\
\hline
\end{tabular}




\section{Al-Yasiri et al. / Basrah J. Agric. Sci., 32(Spec. Issue 2): 360-372, 2019}

The polynomial formulas 15 and 16, with a coefficient of 0.920 and 0.960 ; were used at the beginning and end of the growing season, respectively, to predict saturated water conductivity values as a function of soil

$$
\begin{aligned}
& k s_{i}=0.307+0.065 Q-0.008 D\left(R^{2}=0.920\right) \ldots \\
& K s_{e}=0.403+0.073 Q-0.010 D\left(R^{2}=0.960\right) \ldots
\end{aligned}
$$

The results in tables (2-4) showed that there is a significant effect of the triple interaction among the emitter discharge treatments and the distance between the emitters according to the length of the field pipe in the values of saturated hydraulic conductivity at the beginning and end of the growing season. A significant increase in the values of saturated hydraulic conductivity at the interactions between the emitter treatment of $8 \mathrm{~L}^{-\mathrm{hr}^{-1}}$, the distance between the emitters was $20 \mathrm{~cm}$ for all pipe lengths 10, 15 and $20 \mathrm{~m}$, compared with the corresponding interventions at the rest of the discharges $6,4,2 \mathrm{~L}^{-1} \mathrm{hr}^{-1}$, the distances between emitters were 30 and 40 $\mathrm{cm}$. The highest values were recorded when

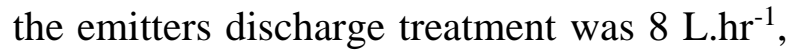
the distance between the emitters was $20 \mathrm{~cm}$ using the $10 \mathrm{~m}$ field length of 0.937 and 1.142 m.day ${ }^{-1}$ at the beginning and end of the growing season, respectively. Whereas the lowest values at the treatment were the emitter discharge 2 L.hr $^{-1}$ and the distance between the emitters $40 \mathrm{~cm}$ at the length of the pipe $20 \mathrm{~m}$ by 0.192 and $0.282 \mathrm{~m}^{-d_{a y}}{ }^{-1}$ at the beginning and end of the growing season, respectively. This is due to the increased discharge of the emitters and the lack of both the distance between the emitters and the length of the field pipe, leads to the availability of moisture, salt washing and saturation conditions. The relationship between the values of saturated hydraulic conductivity as a function increased growth of the root system of the plant, provides a suitable environment for increasing the volume of soil pores responsible for the movement of water under of the emitter discharge factors and the distance between the emitters and the length of the field pipe using equations 17 and 18 were the beginning and end of growing season with a coefficient of determination of 0.964 and 0.963 respectively, increased the values of the saturated hydraulic conductivity by increase the emitter discharge and the small distance between the emitters and the length of the field pipe.

The results in tables (2, 3 and 4) also showed that there were no significant effect of the rest of the interactions, triple and quadratic interactions on the values of saturated hydraulic conductivity at the beginning and end of season.

$$
\begin{aligned}
K s_{i} & =0.799+0.066 Q-0.008-0.022 L\left(R^{2}=0.964\right) \ldots \\
K s_{e} & =1.005+0.073 Q-0.012 S-0.022 L\left(R^{2}=0.963\right) \ldots
\end{aligned}
$$




\section{Al-Yasiri et al. / Basrah J. Agric. Sci., 32(Spec. Issue 2): 360-372, 2019}

\section{Conclusion}

We conclude from the above that increasing the emitter discharge and reducing the distance between the emitter and the length of the field tube leads to an increase in the conductivity of water saturated. Therefore, we recommend the use of the emitter discharge 8 L. $\mathrm{hr}^{-1}$ and the distance between the emitter 20 $\mathrm{cm}$ and the length of the field tube $10 \mathrm{~m}$.

\section{Acknowledgements}

The author thanks the Department of Soil Sciences and Water Resource, College of Agriculture, University of Basrah.

Conflict of interest: The authors declare that they have no conflict of interest.

\section{References}

Abdul Rahman, J.N. \& Al-Sheikhli, A.H. (2011). Effect of period and level of irrigation and emitter discharge on tip rate in clay soils. Iraqi J. Agric. Sci., 42(Spec. Issue): 108-125. (In Arabic)

Al-Abdali, Z.F.H. (2019). Effect of some hydraulic properties of drip irrigation system and soil surface slope on some physical soil properties and tomato growth and yield (Lycopersion esculentum Mill). Master. Sc. Thesis. Coll. Agric., Univ. Anbar: 111pp. (In Arabic)

Al-Brahimi, M.S.B. (2014). Effect of irrigation level and rotation of emitter discharge for irrigation or irrigation cycle on some physical properties of clay soils and growth of maize plant (Zea mays L.). Ph. D. thesis. Coll. Agric. Univ. Basrah. 157pp. (In Arabic)

Al-Sadoun, J.N.A. (2006). Effect of some standards of drip irrigation on water and salts distribution in clay sedimentary soils and on growth and production of okra crop. Ph. D. thesis. Coll. Agric. Univ. Baghdad: 150pp. (In Arabic).

Atee, A.S. (2009). Influence of organic matter and aggregation size on the soil aggregate stability and saturated hydraulic conductivity. J. Tikrit Univ. Agric. Sci., 9(2): 131-139.

Black, C.A.; Evans D.D.; White L.L.; Ensminger L.E. \& Clark, F.E. (1965). Method of Soil Analysis, Am. Soc. of Agron. Madison, Wisconsin, USA. No. 9 part I and II. : 1143 pp.

Camillia, Y.E.; Dewiny, L.; Moursy K.H.S.; \& El-Aila, H.I. (2006). Effect of matter on the release and availability of phosphorus and their effects on Spanish and radish plants. Journal. Agric. Biol. Sci., 2(3): 103108.

Ekhmaj, A.I. \& Abdulaziz, A.M. (2008). Trickle irrigation as a simple tool to estimate saturated hydraulic conductivity. $12^{\text {th }}$ Int. Water Tech. Conf., IWTC12 2008 Alexandria: 1-9.

Evenylo, G. \& Meguinn, R. (2000). Agricultural management practices: Measuring, assessing and comparing laboratory and field-test kit indicators of soil quality attributes. Virginia Cooperative Extension Virginia Estate University. Publ.No.400-425 March: 1-9.

Ghanimi, M.I. \& Al-Zuhairi A.M., (2015). Irrigation Water Management. Coll. Agric., Al Qussaim Univ.: 32pp. (In Arabic)

Hassan, W.B. (2018). Effect of emulsified oil enhancers and dripper expenses under different moisture levels on some physical soil characteristics and growth and production of sunflower. Ph. D. Thesis. Coll. Agric., Univ. Basrah: 158pp. (In 
Al-Yasiri et al. / Basrah J. Agric. Sci., 32(Spec. Issue 2): 360-372, 2019 Arabic)

Sarhan, A.M. (2009). Effect of irrigation schedules under drip irrigation system on salt and moisture distribution in soil affected by salinity. M. Sc. Thesis. Coll. Agric. Univ. Baghdad: 108 pp. (In Arabic).

Schwartzman, M. \& Zur, B. (1986). Emitter spacing and geometry of wetted soil. J. Irrig. Drain. ASCE., 112 (3): 242-253.

Young, E.G.; Leeds, P.B.; Arison H. \& Garmett R.S. (1994). Water uptake by aggregates. European. J. Soil Sci., 45: 127133. 